\title{
Interaction of membrane palmitoylated protein-1 with model lipid membranes
}

\author{
Mohamed Elderdfi and Aleksander F. Sikorski \\ Department of Cytobiochemistry, Faculty of Biotechnology, University of Wrocław, 50-383 Wrocław, Poland
}

\begin{abstract}
Membrane palmitoylated protein-1 (MPP1) plays an important role in the formation of raft domains in erythroid membranes. We have shown recently that MPP1 interacts with membrane lipids composed of dioleoylphosphatidylcholine (DOPC), sphingomyelin (SM) and cholesterol. Here we further extend this investigation. Our results obtained from FRET assays revealed that MPP1 binds liposomes with high affinity $\left(\mathrm{K}_{\mathrm{D}} \sim 135 \pm 15 \mathrm{nM}\right)$. Preincubation of MPP1 with cholesterol before its addition to the Langmuir subphase resulted in a dramatic reduction in the membrane insertion/binding of MPP1, indicating the role of direct MPP1/cholesterol complexes in the interaction of MPP1 with membrane lipids. The generalized polarization values of liposomes as well as the constant surface area experiments on monolayers composed of DOPC/SM/Chol indicated a change in the lipid mono- and bilayer properties upon the addition of MPP1. Furthermore, the presence of flotillins did not affect the binding of MPP1 to membrane lipids. Also, MPP1 containing palmitoylation-mimicking mutation $(\mathrm{C} 242 \mathrm{~F})$ bound DOPC/SM/Chol mono- and bilayer with an affinity very similar to that obtained for wild-type MPP1. In conclusion, our results suggest that the direct binding of MPP1 with membrane lipids could be involved in the mechanism of membrane association of MPP1 in erythroid cells.
\end{abstract}

Key words: Membrane palmitoylated protein 1 - FRET assay — Protein-lipid interactions — Membrane lipid order — Langmuir monolayer

\section{Introduction}

The lateral association of membrane proteins in the plasma membrane and the formation of functional domains (cholesterol-rich "raft-like" domains) have emerged as key concepts in cell biology (Khan et al. 2003). The formation and maintenance of such domains in the plasma membrane require segregation of different types of protein and lipid membrane components by a variety of specific lipid-lipid, lipid-protein and protein-protein interactions (Gómez-Móuton et al. 2001; Seveau et al. 2001; Xu et al. 2003; Hancock 2006; Simons and

Electronic supplementary material. The online version of this article (doi: 10.4149/gpb_2018029) contains supplementary material, which is available to authorized users.

Correspondence to: Aleksander F. Sikorski, Department of Cytobiochemistry, Faculty of Biotechnology, University of Wrocław, 50-383, Wrocław, Poland

E-mail: aleksander.sikorski@uwr.edu.pl
Gerl 2010; Levental et al. 2011; Bernardino de la Serna et al. 2016; Carquin et al. 2016). There is a general consensus that the major challenge in the formation of raft-like domains is to understand the molecular mechanism of their action in an endogenous cellular context. Lateral interactions of cholesterol with membrane lipid rafts, in particular sphingolipids, are believed to play a central role in maintaining these domains in a liquid-ordered phase. Nevertheless, besides cholesterol and sphingolipids, membrane rafts also contain other lipids such as glycolipids and specific inner-layer phospholipids in addition to many proteins.

The membrane interface is a complex region with both lipid head groups and water molecules. Proteins may associate with the membrane rafts by direct interaction with cholesterol molecules. Apart from the cholesterol-binding property, the partitioning of proteins into membrane raft domains may also involve other mechanisms such as preferential interaction with particular raft lipids, i.e. acylation with myristic or palmitic acids (Epand 2008), or may occur indirectly as a consequence of interaction of the protein 
with scaffolding proteins, i.e. caveolin and flotillins (Head et al. 2014).

One family of scaffolding proteins is the MAGUK group (membrane-associated guanylate kinase homologs). This family of proteins has been proposed to be crucial in segregating specific molecules to specific domains in the plasma membrane by formation of multi-complexes with other proteins (Dimitratos et al. 1999). Membrane palmitoylated protein 1 (MPP1), a member of the MAGUK family, has been identified as a membrane skeleton protein in erythrocytes by constituting a ternary complex with glycophorin $\mathrm{C}$ and protein 4.1 (Hemming et al. 1995; Marfatia et al. 1997; Seo et al. 2009). Published data have revealed that MPP1 plays a fundamental role in the lateral membrane organization in native erythroid cells (Biernatowska et al. 2013; Podkalicka et al. 2015). Flotillins are predominantly found among the protein components of erythrocyte membrane raft domains, and are believed to play an important role in the stabilization of lateral membrane organization (Salzer and Prohaska 2001). Recently flotillin-1 and flotillin-2 have been shown to be direct binding partners of MPP1 in erythrocyte membranes (Biernatowska et al. 2017). Therefore, a possible mechanism of the direct raft association of MPP1, apart from the above-mentioned role of MPP1 in strengthening protein 4.1-glycophorin C binding, has been proposed (Sikorski et al. 2015).

There has been extensive work on defining the composition of lipid mixtures that exhibit lipid lateral heterogeneity to imitate the phase separation of raft-like domains in biological membranes. An example of such lipid mixtures is one with equimolar amounts of dioleoylphosphatidylcholine (DOPC), sphingomyelin (SM), and cholesterol (Chol). This ternary lipid mixture has been widely studied by many techniques for its ability to form two immiscible liquid domains containing more ordered domains that consist mainly of SM/ Chol surrounded by domains in a more liquid state (Edidin 2003; Goñi et al. 2008; Fritzsching et al. 2013; Maté et al. 2014; Efimova and Ostroumova 2017; Bhojoo et al. 2018; Henry et al. 2018; Parkkila et al. 2018; Paulowski et al. 2018). Significantly, we have recently shown that MPP1 interacts with lipid mono- and bilayers in artificial systems composed of this ternary lipid mixture (DOPC/SM/Chol) (Elderdfi et al. 2017). Furthermore, this interaction was affected by the presence of cholesterol in the lipid mixture (Elderdfi et al. 2017), raising a vital question about the physiological importance of such interactions.

The present study aimed, therefore, to further explore the effect of cholesterol, lateral phase heterogeneity and flotillins on binding properties of MPP1 with lipid mono- and bilayers. We also tested the effect of this interaction on the physical properties of mono- and bilayers. We present experimental evidence of a direct interaction between MPP1 and cholesterol molecules, observable as inhibition of the binding of MPP1 with lipid monolayers after pre-incubation of MPP1 with cholesterol. In addition, our results indicate that the modifications in the lipid order upon addition of MPP1 were sensitive to subtle changes in the phase state of the lipid mixture. Our results suggest that the direct binding of MPP1 with membrane lipids could be involved in the mechanism of membrane association of MPP1 in erythroid cells and possibly participate in the molecular mechanism of regulation of lateral membrane organization.

\section{Materials and Methods}

\section{Recombinant proteins}

Recombinant proteins, wild type MPP1 and C242F mutant mimicking palmitoylated MPP1 (F-MPP1), flotillin-1 and flotillin-2, were obtained by cloning the coding regions of human MPP1, flotillin-1 and flotillin-2 into pRSET A as previously described (Biernatowska et al. 2017; Elderdfi et al. 2017). The $\mathrm{C} 242 \mathrm{~F}$ mutant mimicking palmitoylated MPP1 (F-MPP1) was generated by Dr. Katarzyna Augoff. The use of such a mutant was suggested elsewhere (Ruff et al. 1991; Yang et al. 2010). The concentration of the proteins was determined using an absorbance coefficient at $280 \mathrm{~nm}$ calculated using the ExPASy ProtParam program (Wilkins et al. 1999).

\section{Lipids}

Sphingomyelin (egg), 1,2-dioleoyl-sn-glycero-3-phosphocholine (DOPC), 1,2-dipalmitoyl-sn-glycero-3-phosphocholine (DPPC), 1-palmitoyl-2-oleoyl-sn-glycero-3-phosphocholine (POPC), 1,2-dioleoyl-sn-glycero-3-phosphoethanolamine (DOPE), 1-palmitoyl-2-oleoyl-sn-glycero-3-phosphate (POPA), 1,2-dioleoyl-sn-glycero-3-phosphoserine (DOPS), and 1,2-dioleoyl-sn-glycero-3-phosphoethanolamine-N-(5-dimethylamino-1-naphthalenesulfonyl) (dansyl-PE) were purchased from Avanti Polar Lipids and cholesterol (Chol) was obtained from Northern Lipids. The phospholipid concentrations were quantified by phosphorus analysis, (Rouser et al. 1966) whereas cholesterol concentration was quantified using a Cholesterol Kit (BioSystems).

\section{Liposome preparation}

Liposomes were prepared by the hydration of a dry lipid film as previously described (Bangham et al. 1965; Elderdfi et al. 2017). Briefly, the organic solvents were evaporated under a nitrogen atmosphere to obtain a thin lipid film. The film was then further dried under vacuum for at least 2 hours. The lipids were re-suspended in HEPES buffered saline (HBS) (20 mM HEPES, $150 \mathrm{mM} \mathrm{NaCl}, \mathrm{pH}$ 7.4) to a concentration 
of $1 \mathrm{mg} / \mathrm{ml}$. The hydrated liposomal suspension was subsequently extruded through a $0.4 \mu \mathrm{m}$ polycarbonate membrane filter. The filter was then sequentially replaced by $0.2 \mu \mathrm{m}$ and $0.1 \mu \mathrm{m}$-pore membranes, and the extrusion cycles were repeated 10 times independently for each filter. The size of the liposomes was determined using a ZetaSizer (Malvern).

Liposomes in this study were prepared from four lipid mixtures: i) lipid liposomes exhibiting the formation of phase-separated domains were assessed using a lipid mixture composed of DOPC, SM and Chol at a 1:1:1 molar ratio, hereinafter called "DOPC-containing liposomes" (Maté et al. 2014), ii) lipid liposomes without cholesterol were prepared using a lipid mixture composed of DOPC and SM at a 1:1 molar ratio, iii) lipid liposomes exhibiting a homogeneous phase were prepared using a lipid mixture composed of DPPC, SM and Chol at a 1:1:1 molar ratio, hereinafter called "DPPC-containing liposomes", iv) lipid liposomes similar to the inner leaflet of the erythrocyte-lipid plasma membrane were assessed using a lipid mixture composed of DOPE, POPA, POPS, SM, POPC and Chol at a 30:2:20:9:10:27.5 molar ratio (DeWolf et al. 1997; Virtanen et al. 1998), hereinafter called "erythrocyte-like liposomes".

\section{Flotation assays}

The flotation assay was performed as previously described (Busse et al. 2013; Elderdfi et al. 2017; Tronchere and Boal 2017). Briefly, proteins (MPP1 or flotillin-1 or flotillin-2) at a concentration of $50 \mathrm{nM}$ were prepared with $0.4 \mathrm{mg} / \mathrm{ml}$ lipid liposomes in HBS buffer to a final volume of $250 \mu \mathrm{l}$ and incubated at room temperature for 30 minutes. Control samples contained only protein without liposomes at the same concentration. After incubation, samples were transferred to ultracentrifuge tubes and mixed with $250 \mu \mathrm{l}$ of $60 \%$ sucrose by pipetting up and down a few times. The samples were carefully overlaid with $0.8 \mathrm{ml}$ of $15 \%$ sucrose, followed by $1.8 \mathrm{ml}$ of $10 \%$ sucrose in HBS buffer, and finally with $1.0 \mathrm{ml}$ of HBS buffer without mixing, so as to establish a sucrose gradient. The samples were then centrifuged at $200000 \times g(45000 \mathrm{rpm}, 60 \mathrm{Ti}$ rotor $)$ for 2 hours at $4^{\circ} \mathrm{C}$. After centrifugation, 6 fractions were taken via collection sequentially from the top and, after addition of SDS to a final concentration of $1 \%$, fractions were analyzed via dot-blot assay. Equal volumes of samples were loaded into the wells of a dot-blotter (Hoefer Scientific Instruments) and transferred onto a nitrocellulose membrane by vacuum filtration, after which the membrane was blocked for $60 \mathrm{~min}$ at room temperature. Detection of bound protein was performed using the desired antibodies, namely, mouse monoclonal anti-MPP1 antibodies for MPP1 (Abnova, CA, USA), rabbit anti-flotillin-1 antibodies for flotillin-1 (Santa Cruz Biotechnology, Inc., Heidelberg, Germany), or goat anti-flotillin-2 antibodies for flotillin-2 (Santa Cruz Biotechnology, Inc.,
Heidelberg, Germany), followed by chemiluminescence analysis performed on a UVP Imaging System.

The band intensity of the dot blot was quantified using image analysis software (ImageJ) in order to compare the binding of MPP1 towards DOPC- and DPPC-containing liposomes, as previously described (Boal et al. 2015; Tronchere and Boal 2017).

\section{Förster resonance energy transfer binding assay (FRET)}

We performed steady-state experiments, in which the fluorescence emission intensity of dansyl-labeled liposomes was measured using a Cary Eclipse fluorescence spectrophotometer equipped with a temperature controller (Varian) in a $45 \times 12.5 \times 12.5 \mathrm{~mm}$ quartz cuvette at $22^{\circ} \mathrm{C}$. Tryptophandansyl FRET-detected binding of increasing concentrations of MPP1 or F-MPP1 (tryptophan residues "donor") to lipid liposomes containing 3\% dansyl-PE (dansyl-labeled liposome "acceptor") was performed as described previously (Gilbert et al. 1990). The total lipid concentration for the measurement was $10 \mu \mathrm{M}$ and MPP1 was added in increments. An excitation wavelength of $295 \mathrm{~nm}$ was applied. The emission intensity at the dansyl emission maximum $(525 \mathrm{~nm})$ was monitored in the presence of different protein concentrations. The dansyl fluorescence increase, from the average of the maximum emission intensity enhancement of the acceptor signal in the presence of the donor, was calculated from the equation (White and Holcombe 2007): Dansyl fluorescence increase $(\%)=\left(I_{d n s+m p p 1} / I_{d n s}-1\right) \times 100$, where $I_{d n s+m p p 1}$ is the fluorescence intensity of the acceptor in the presence of the donor and $I_{d n s}$ is the fluorescence intensity of the acceptor in the absence of the donor ( $0 \%$ increase).

GraphPad PRISM 6 software was used to calculate the equilibrium dissociation constant $\left(\mathrm{K}_{\mathrm{D}}\right)$ value of the binding affinity of MPP1 with lipid liposomes from the hyperbolic curve obtained from FRET assay data using a nonlinear regression curve fit.

\section{Langmuir monolayer studies}

Experiments measuring the change in surface pressure upon injection of the protein into the subphase were performed by the Wilhelmy technique, using a Teflon trough (surface area) and a Nima tensiometer (Nima Technology, Coventry, UK), at room temperature. The entire instrument was enclosed in a box, facilitating flushing with a stream of nitrogen. For the surface activity of MPP1 at the air/buffer interface, $500 \mu \mathrm{l}$ aliquots of increasing concentrations of MPP1 previously dialyzed against the subphase buffer were injected into the Langmuir subphase buffer (Tris/ $\mathrm{HCl}, \mathrm{pH} 7.5,0.5 \mathrm{mM}$ EDTA, $150 \mathrm{mM} \mathrm{NaCl}$ and $0.5 \mathrm{mM}$ dithiothreitol) through a lateral hole under continuous stirring of the subphase, and the adsorption of the protein at the air/buffer interface was 
recorded as an increase in surface pressure $(\Delta \pi)$ versus time until it remained constant.

To assess the insertion of protein into lipid monolayers, the kinetics of insertion of the protein into lipid monolayers were measured using the same trough as for the surface activity. For these experiments, a $0.5 \mathrm{mg} / \mathrm{ml}$ lipid stock solution of the lipid mixture was prepared and added dropwise on the subphase until the desired lipid initial surface pressure was achieved. After 15-20 min, the equilibrium of the lipid monolayer was reached. Then, a $500 \mu$ protein solution was injected into the subphase through the side hole of the trough. The subphase was stirred with a small $(1 \times 3 \mathrm{~mm})$ magnetic stirrer during the measurements, and surface pressure changes were monitored as a function of time. GraphPad PRISM 6 software was used for the surface activity curve of MPP1, using a nonlinear regression curve fit, and the equilibrium protein concentration was calculated as previously described (Elderdfi and Sikorski 2018).

For inhibition of lipid-MPP1 interactions by cholesterol, a total of $50 \mu \mathrm{l}$ chloroform solution of the cholesterol solution was added to a glass test tube and chloroform was removed using a nitrogen stream for around 30 minutes (Hossain et al. 2016). Then, a $500 \mu \mathrm{l}$ MPP1 solution was added to the cholesterol film and incubated for 30 minutes at room temperature with gentle shaking prior to its injection into the subphase buffer of an erythrocyte membrane-like monolayer at an initial surface pressure of $20 \mathrm{mNm}^{-1}$. As a control, an identical treatment was also applied for samples containing MPP1, but the test-tube did not contain cholesterol when the same volume of chloroform was evaporated. The final MPP1 concentration in the subphase was $10 \mathrm{nM}$. A reference sample of either a $500 \mu \mathrm{l}$ buffer alone ( 0 nM MPP1) or cholesterol in the same buffer was used. The percentage of the insertion efficiency of MPP1 was calculated from the equation: Insertion efficiency of MPP1 $(\%)=\Delta \pi_{m p p 1+c h o l} /$ $\Delta \pi_{m p p 1} \times 100$, where $\Delta \pi_{m p p 1+c h o l}$ and $\Delta \pi_{m p p 1}$ are pre-incubated MPP1 with and without cholesterol, respectively. The $\Delta \pi_{m p p 1}$ without cholesterol was considered as having $100 \%$ insertion efficiency of protein. For clarity, the quantitative and qualitative analyses of pre-incubated MPP1 protein samples with and without cholesterol after high speed centrifugation at $10,000 \mathrm{rpm}$ for 10 minutes to remove any precipitated material were performed using SDS-PAGE, the absorption spectrum, and the autofluorescence properties of preincubated-MPP1 samples with and without cholesterol. The results confirmed that the protein remained soluble (see Supplementary Material Fig. S1 and S2).

\section{Fluorescence spectroscopy measurements}

Liposomes were labeled with C-Laurdan (dissolved in ethanol). After addition of the probe to the final concentration, the sample was briefly vortexed and incubated in the dark for at least 30 minutes to ensure homogeneous dye incorporation into the liposomes before the fluorometric measurement (0.2 mol\% C-Laurdan). Steady-state emission spectra were acquired in a Cary Eclipse fluorescence spectrophotometer. Fluorescence emission spectra were recorded and analyzed as previously described (Sezgin et al. 2014). The excitation wavelength for C-Laurdan was $385 \mathrm{~nm}$ and the emission spectrum was collected from 410 to $550 \mathrm{~nm}$. The generalized polarization (GP) measurements of C-Laurdan were calculated as a relative measure for membrane order from the formula: $G P=\left(I_{\lambda \text { ordered }}-I_{\lambda \text { disordered }}\right) /\left(I_{\lambda \text { ordered }}+\right.$ $\left.I_{\lambda \text { disordered }}\right)$, where $I_{\lambda \text { ordered }}$ and $I_{\lambda \text { disordered }}$ are the emission intensities of the ordered emission band and the disordered emission band, respectively. Standard deviation (SD) and Student's $t$-test were used to assess the variability of obtained data applying MS Excel procedures.

\section{Results}

\section{Influence of changing the lipid environment on binding activity of MPP1 with membrane lipids}

\section{Affinity of interaction of MPP1 and C242F mutant mimicking palmitoylated MPP1 with membrane lipids}

In our previous study (Elderdfi et al. 2017) we demonstrated that recombinant MPP1 binds to liposomes and penetrates DOPC/SM/Chol monolayers. To gain a more quantitative insight into the binding of MPP1 to membrane lipids, the binding of MPP1 with lipid liposomes composed of equimolar ratios of a DOPC/SM/Chol or DOPC/SM mixture was investigated using Förster resonance energy transfer (FRET) (Fig. 1A). Endogenous tryptophan residues in MPP1 were used as FRET donors for a dansyl-labeled acceptor (dansyl-PE) distributed randomly on the target liposome surface. The FRET-based assay resulting from binding of MPP1 and membrane lipids was determined from the increase in the intensity of the tryptophan-excited dansyl emission upon addition of increasing amounts of protein (see Materials and Methods). The results of FRET-based assay dependence on MPP1 concentration are shown in Fig. $1 \mathrm{~A}$ and $1 \mathrm{~B}$. As the concentration of MPP1 was increased, enhancement of the dansyl fluorescence increase was observed, clearly showing that the energy-transfer increase was dependent on the concentration of the donor. The equilibrium dissociation constant $\left(\mathrm{K}_{\mathrm{D}}\right)$ value of the interaction of the MPP1 protein with DOPC/SM/Chol-liposomes and DOPC/SM-liposomes obtained in these experiments was $135 \pm 25 \mathrm{nM}$ and $220 \pm 47 \mathrm{nM}$, respectively.

Previous studies have reported that palmitoylation plays a role in the association of some membrane proteins with the plasma membrane (Epand 2008). We further investi- 
gated whether palmitoylation is required for the binding of MPP1 with lipid mono- or bilayers in two separate model systems, namely FRET assay using liposomes, or with a lipid monolayer at the air/buffer interface using the Langmuir monolayer technique. As shown in Fig. $1 \mathrm{C}$, the $\mathrm{K}_{\mathrm{D}}$ value obtained from the interaction of the $\mathrm{C} 242 \mathrm{~F}$ mutant mimicking palmitoylated MPP1 (F-MPP1) with DOPC/SM/Cholliposomes using FRET assay experiments was $136 \pm 26 \mathrm{nM}$. In addition, to compare further lipid-binding properties of MPP1 and the F-MPP1 mutant, the exclusion surface pressure resulting from the penetration ability of both proteins into lipid monolayers was measured. As shown in Fig. 1D, the increase in the surface pressure $(\Delta \pi)$ in monolayers upon the addition of MPP1 to the subphase buffer at various initial surface pressures $\left(\Delta \pi=\pi_{f i n a l}-\pi_{\text {initial }}\right)$ was essentially the same as for the F-MPP1 mutant. The determined exclusion surface pressure (the surface pressure above which the pro- tein does not penetrate into the lipid monolayer) for MPP1 and F-MPP1 was 26 and $27 \mathrm{mNm}^{-1}$, respectively. These results suggest that the mutation of cysteine 242 to phenylalanine has no effect on the insertion/binding of MPP1 to artificial lipid membranes.

\section{Effect of cholesterol on binding activity of MPP1 with membrane lipids}

Previously we have shown that the interaction of MPP1 and membrane lipids is sensitive to the presence of cholesterol, by observing the effect of MPP1 on DOPC/SM/Chol monolayers compared to cholesterol-free monolayers (DOPC/SM) (Elderdfi et al. 2017). However, the role of cholesterol in the MPP1-membrane interaction remains poorly understood. Hence, Langmuir experiments were designed to further elucidate whether cholesterol is able to inhibit the interac-
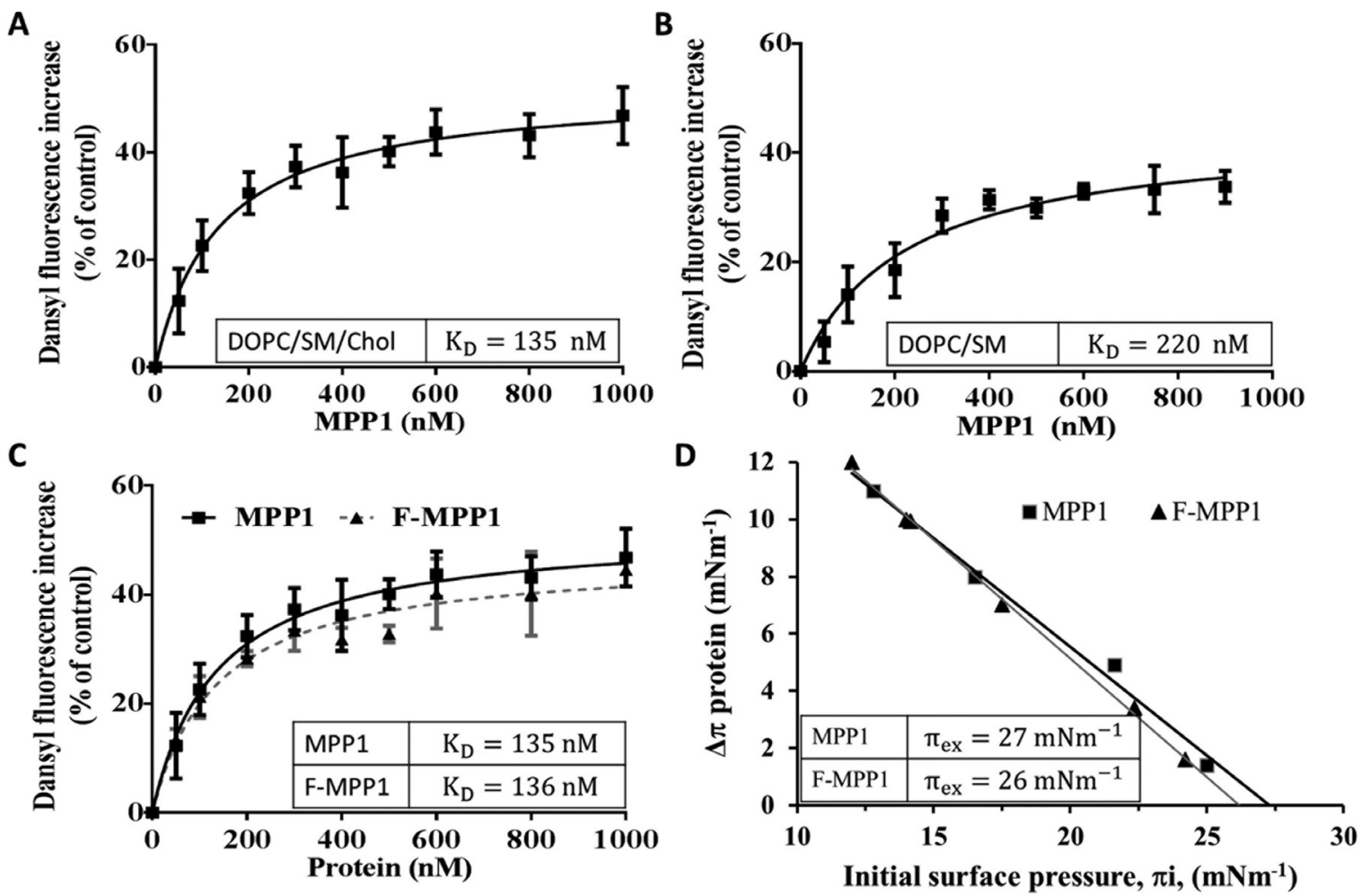

Figure 1. Interaction of MPP1 with lipid membranes. A. FRET-based assay; an increase in dansyl-lipid fluorescence emission intensity upon addition of increasing amounts of MPP1 to lipid liposomes composed of DOPC, SM and cholesterol was measured. Corresponding $\mathrm{K}_{\mathrm{D}}$ and $r^{2}$ were $135 \pm 15 \mathrm{nM}$ (error values, standard error of fit) and 0.99 , respectively. B. FRET-based results of binding of MPP1 to lipid liposomes composed of DOPC and SM. Corresponding $\mathrm{K}_{\mathrm{D}}$ and $r^{2}$ were $220 \pm 47 \mathrm{nM}$ (error values, standard error of fit) and 0.97, respectively. C. FRET-based results of binding of MPP1 and its C242F mutant mimicking palmitoylated MPP1 (F-MPP1) to lipid liposomes composed of DOPC, SM and cholesterol. Corresponding $\mathrm{K}_{\mathrm{D}}$ and $r^{2}$ for binding of F-MPP1 were $136 \pm 26 \mathrm{nM}$ and 0.97 , respectively. D. Determination of exclusion surface pressures $\left(\pi_{e x}\right)$, change in surface pressure $\left(\pi_{f i n a l}-\pi_{\text {initial }}\right)$ vs. initial surface pressure $\left(\pi_{\text {initial }}\right)$, for MPP1 (black squares) in comparison with F-MPP1 (grey triangles) adsorption on a lipid monolayer composed of DOPC, SM and cholesterol. FRET assay data here are presented as mean \pm SD $(n=3)$. MPP1, membrane palmitoylated protein-1; FRET, Förster resonance energy transfer binding assay; DOPC, dioleoylphosphatidylcholine; SM, sphingomyelin. 
A

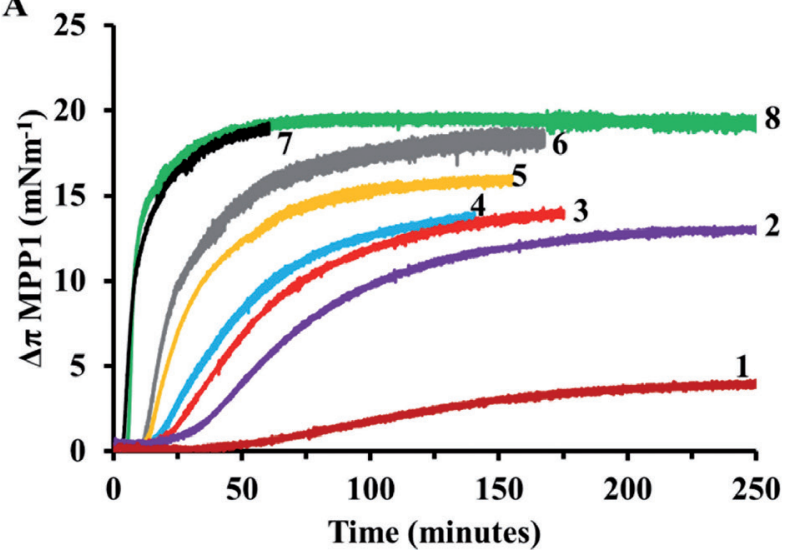

B

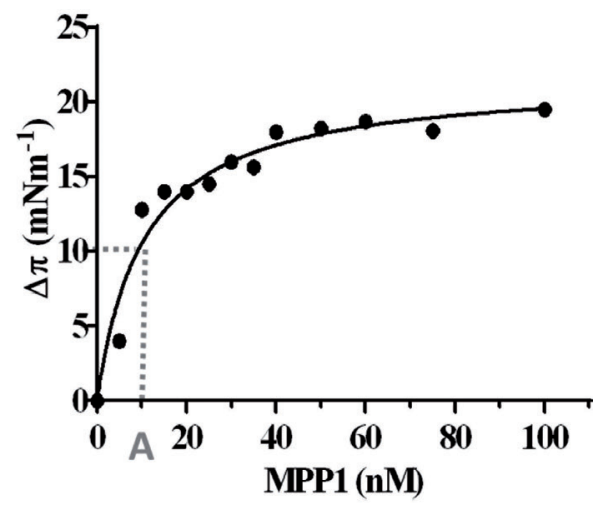

Figure 2. Protein surface-adsorption activity. A. MPP1 surface adsorption kinetics at the air/buffer interface at different protein concentrations. Line 1, $5 \mathrm{nM}$; line 2, $10 \mathrm{nM}$; line 3, $15 \mathrm{nM}$; line 4, $20 \mathrm{nM}$; line 5, $30 \mathrm{nM}$; line 6, $40 \mathrm{nM}$; line 7, $60 \mathrm{nM}$; line 8, $100 \mathrm{nM}$ MPP1. B. Corresponding surface-activity curve of MPP1 as a function of protein concentration. A at axis $\mathrm{x}$ is the extrapolated protein concentration equal to the protein concentration that achieves $1 / 2 \Delta \pi_{\max }$. Data in the surface-activity curve represent the equilibrium values derived from the surface adsorption plots shown in panel A. $\pi$, surface pressure.

tion between MPP1 and lipid monolayers. First, protein surface activity for the adsorption of MPP1 into the air/ buffer interface at different protein concentrations in the subphase was assessed. Figs. 2A and 2B show the adsorption kinetic process and the corresponding surface activity curve of MPP1, respectively. A nonlinear regression curve fit was used to fit the data of the surface activity $v s$. protein concentration in the subphase, according to the following equation: $\Delta \pi=C \pi_{\max } /(\mathrm{A}+\mathrm{C})$, where $\mathrm{C}$ is the concentration of MPP1 in the subphase (nM), $\pi_{\max }$ is the maximum surface pressure, and $\mathrm{A}$ is a characteristic constant equal to the protein concentration which achieves $1 / 2 \Delta \pi_{\max }$. The calculated A and $\pi_{\max }$ values obtained from the surface activity curve were $10.7 \mathrm{nM}$ and $21 \mathrm{mNm}^{-1}$, respectively $\left(r^{2}=0.95\right)$. This protein concentration $(10 \mathrm{nM})$ is lower than the equilibrium spreading surface pressure of the protein and, importantly, it is the appropriate protein concentration that was chosen for the insertion study (Sánchez-Martín et al. 2010).
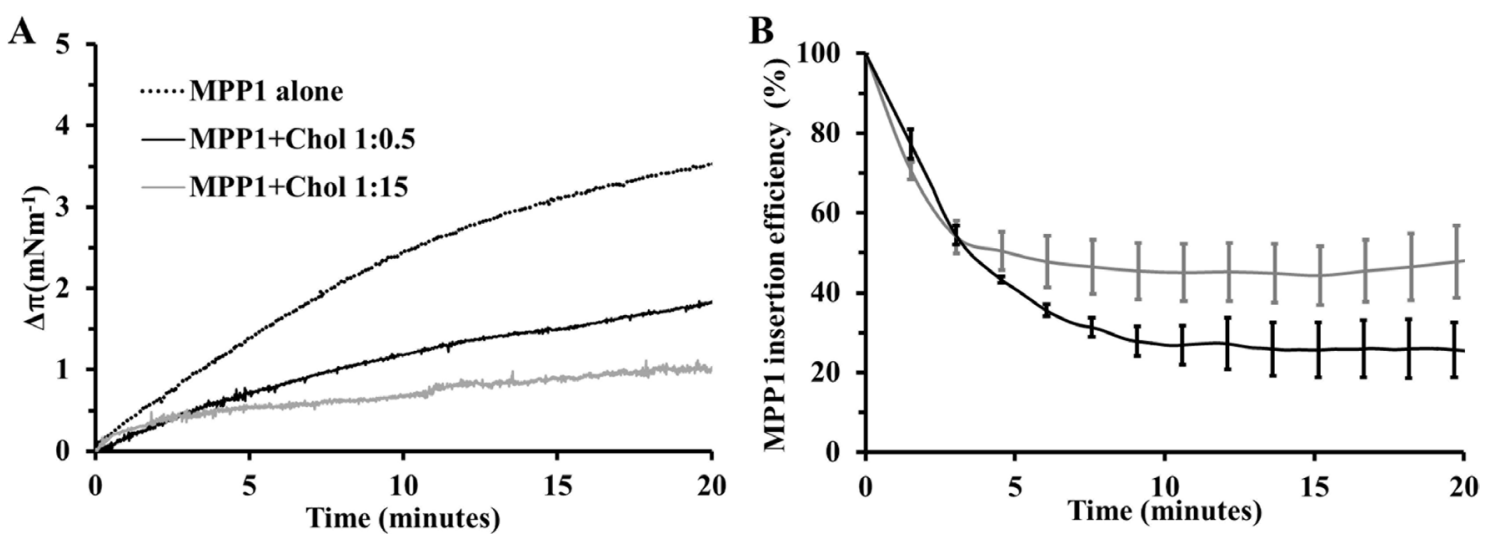

Figure 3. Effect of cholesterol on binding activity of MPP1 with erythrocyte membrane-like lipid monolayer using a Langmuir monolayer constant surface area study. A. Change in surface pressure $(\Delta \pi)$ of erythrocyte membrane-like monolayers after addition of pre-incubated MPP1 without cholesterol (dotted black line) and pre-incubated MPP1 with cholesterol at molar ratio 1:15 (grey line) and 1:0.5 (black line) into the subphase at a given initial surface pressure of $20 \mathrm{mNm}^{-1}$. B. Inhibition of binding of MPP1 to erythrocyte membrane-like monolayers by cholesterol. The data represent the difference in the MPP1 binding activity between the insertion curves of pre-incubated MPP1 with cholesterol and those without cholesterol. For inhibition of lipid-protein interactions by cholesterol, MPP1 was pre-incubated for 30 min without (100\% binding) and with cholesterol, and was then injected into the subphase. The effect of cholesterol in the surface buffer was negligible. Error bars represent SD at particular time points $(n=3)$. 
The membrane penetration ability of MPP1 from the subphase into lipid monolayers at a constant surface area was then determined. The lipid monolayer was formed at the air/buffer interface at a desired initial surface pressure of $\sim 20 \mathrm{mNm}^{-1}$ (the maximal surface adsorption by MPP1 at the air/buffer interface determined from Fig. 2). The change in the surface pressure of the erythrocyte-like monolayers upon the injection of pre-incubated cholesterol-free MPP1 (dotted black line), and pre-incubated-MPP1 with cholesterol (grey and black solid lines) into the buffer subphase against time was monitored (Fig. 3A). The change in the surface pressure of the reference sample containing buffer incubated identically as MPP1 solution over the cholesterol film was negligible. Interestingly, the pre-incubation of MPP1 with cholesterol (at a molar ratio of 1:15 or 1:0.5) significantly reduced the spontaneous membrane insertion of MPP1 into the membrane monolayer in comparison to the insertion of pre-incubated cholesterol-free MPP1 (Fig. $3 \mathrm{~B})$. This finding indicates that the pre-incubation of MPP1 with cholesterol at the solid-liquid interface forms some stable complexes between MPP1 and cholesterol, which in turn prevent MPP1 from inserting into the lipid monolayers at the air/buffer interface.

Effect of lipid lateral heterogeneity on binding of MPP1 with membrane lipid mono- and bilayers

The lateral organization of lipids could be an interesting possibility to explain MPP1 recruitment to lipid raft domains. Because we were unable to detect the effects on the erythrocyte-like membrane model system in the context of its complexity, since it contains several lipids, we reasoned that the effect of lateral phase heterogeneity may be manifested in a well-known and simpler membrane-lipid mixture such as DOPC, SM and cholesterol. This mixture has been shown to exhibit the formation of phase-separated domains (Maté et al. 2014). In addition, previously we have shown that MPP1 interacts with membrane lipids using this particular ternary lipid mixture (Elderdfi et al. 2017). To this end, we therefore investigated the insertion activity of MPP1 into two lipid mixtures that form monolayers of different phase structure under the conditions of our experiment (room temperature), i.e. laterally inhomogeneous, DOPC-containing monolayers composed of DOPC/ SM/Chol and laterally homogeneous DPPC-containing monolayers composed of DPPC/SM/Chol.

At a constant surface area, the insertion of MPP1 from the subphase into DOPC- and DPPC-containing monolayers at the air/buffer interface was investigated at an initial surface pressure of $20 \mathrm{mNm}^{-1}$. Data in Fig, 4A show the change in the surface pressure, $\Delta \pi$, after the addition of $10 \mathrm{nM} \mathrm{MPP} 1$ to the subphase under the lipid monolayers. The final change in the surface pressure of the DOPC-containing (grey bars) or
DPPC-containing (black bars) monolayers after 60 minutes following the injection of MPP1 into the subphase buffer is shown in Fig. $4 \mathrm{~B}\left(\Delta \pi=\pi_{60 \mathrm{~min}}-\pi_{\text {initial }}\right)$. The addition of $10 \mathrm{nM}$ MPP1 to DPPC-containing monolayers induced a greater change in surface pressure $\left(\Delta \pi=5.6 \pm 0.3 \mathrm{mNm}^{-1}\right)$ in comparison with DOPC-containing monolayers $(\Delta \pi=$ $3.4 \pm 0.2 \mathrm{mNm}^{-1}$ ). A possible explanation is proposed in the Discussion section.

Liposome flotation experiments through a sucrose gradient which ensures separation of lipid-bound and free protein were also carried out in order to compare the binding behavior of MPP1 with liposomes prepared from the two above-mentioned lipid mixtures. MPP1 protein was incubated with DOPC/SM/Chol liposomes or DPPC/SM/ Chol liposomes, as described in Materials and Methods. The results obtained from this experiment indicated that the amount of lipid-bound MPP1 detected from the top fraction in the case of DOPC-containing liposomes was greater than those detected in the case of DPPC-containing liposomes (Fig. 4C). For an explanation of this apparent discrepancy, see the Discussion section.

\section{Effect of MPP1 on membrane lipid order}

The extent of lipid packing is one of the key physicochemical features of biological membranes and is involved in many membrane processes. In this study, we further explored the role of MPP1 in membrane organization and whether the presence of MPP1 can alter the degree of lipid packing in bilayers. Generalized polarization (GP) has commonly been used to quantify the spectral behavior of fluorescence probes to estimate the degree of lipid packing of biological membranes. In general, the C-Laurdan fluorescence GP parameter is calculated according to the equation given in Materials and Methods with $440 \mathrm{~nm}$ as the maximum wavelength in ordered membranes (i.e. DPPC) and $490 \mathrm{~nm}$ as the maximum wavelength in disordered membranes (i.e. DOPC). Thus, GP compares the relative packing of a given membrane as the ratio of the emission at these two wavelengths. GP values were obtained by spectroscopy and theoretically assume GP values from -1.0 as the least ordered to 1.0 as the most ordered. In other words, high GP values are obtained when the probe spectrum is blue-shifted and thus indicates a higher order in the bilayer (low penetration of water).

To gain a better understanding of the effect of lipid lateral heterogeneity in biomembranes, we used C-Laurdan to analyze lipid packing in model membranes, namely, DOPC/SM/Chol liposomes or DPPC/SM/Chol, in the absence and presence of MPP1. We measured the GP values of the DOPC-containing liposomes and DPPC-containing liposomes (Figs. 5A and 5B). The emission curves of CLaurdan in both DOPC- and DPPC-containing liposomes were clearly distinguishable from each other under the 


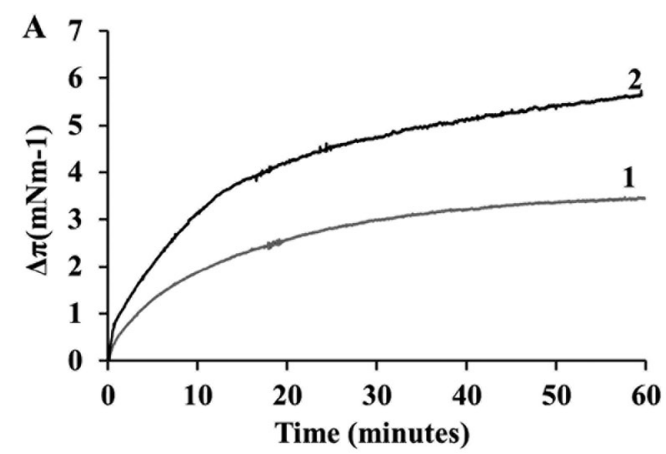

C

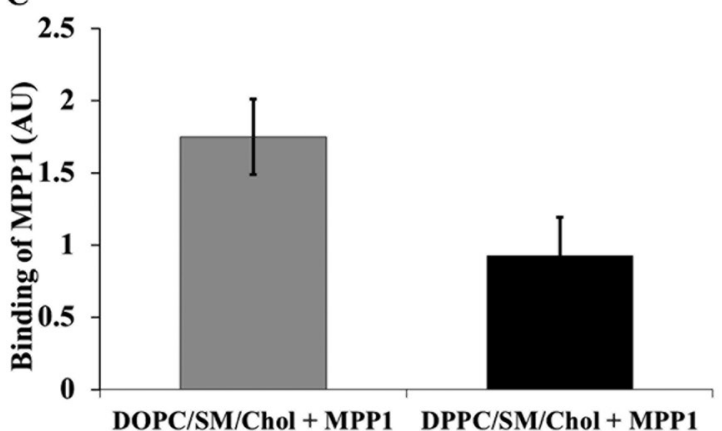

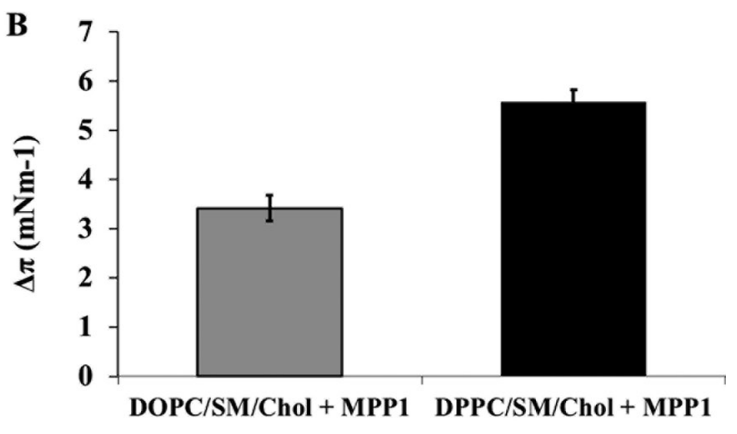

Figure 4. Effect of lipid lateral heterogeneity on the binding activity of MPP1 with membrane lipids. A. Time course of MPP1 insertion into DOPC/SM/Chol (grey, line 1) and DPPC/ $\mathrm{SM} / \mathrm{Chol}$ (black, line 2) monolayers at the air/buffer interfaces at a given initial surface pressure of $20 \mathrm{mNm}^{-1}$ and the protein concentration in the subphase of $10 \mathrm{nM}$. B. Corresponding surface pressure change of DOPC/SM/Chol (grey bars) and DPPC/SM/Chol (black bars) monolayers after 60 minutes following protein injection into the subphase. C. Effect of lateral heterogeneity of lipid mixture composition on binding activity of $50 \mathrm{nM}$ MPP1 to lipid liposomes. Interaction of MPP1

protein with liposomes composed of DOPC/SM/Chol (grey) in comparison with DPPC/SM/Chol (black). Lipid mixtures were analyzed by flotation assays in combination with dot blots. Quantification of all blots was performed using ImageJ software. Student's $t$-test was applied in comparison of the data obtained for DOPC/SM/Chol vs. DPPC/SM/Chol monolayers. ${ }^{*} p<0.05$. Results here are mean \pm SD $(n=3)$. Chol, cholesterol; DPPC, 1,2-dipalmitoyl- sn-glycero-3-phosphocholine. For more abbreviations, see Fig. 1.

conditions of this study. A higher GP value was determined in DPPC-containing liposomes in comparison with DOPCcontaining liposomes, as expected from the known effect of DOPC properties. Although C-Laurdan yields different numerical GP values for these lipid mixtures, the GP sensitivity could still be measured in the presence of MPP1 in each lipid mixture by comparing the GP shift upon the addition of MPP1 with respect to the GP of reference lipid liposomes (either DOPC- or DPPC-containing liposomes). The calculated GP value of DOPC-containing liposomes in the presence of MPP1 was significantly $(p<0.01)$ higher than in its absence, showing that the $\mathrm{C}$-Laurdan probe is in a more rigid environment. On the other hand, the presence of MPP1 in DPPC-containing liposomes did not show a significant effect on the bilayer order. The effect of MPP1 on heterogeneous "phase" artificial lipid bilayers is, therefore, in agreement with our other studies performed on erythroid cell plasma membranes (Podkalicka et al. 2015).

Flotillins as functional partners of MPP1 in the erythroid membrane do not affect binding of MPP1 with membrane lipids although they bind lipid mono- and bilayers

Flotillins are considered as a subpopulation of raft domains in erythrocyte membranes (Salzer and Prohaska
2001). Previous studies have shown that the lipid-binding property of flotillins is mainly related to the prohibitin homology domain (PHB) at the N-terminus, which contains hydrophobic segments (Solis et al. 2007). Even though PHB-containing proteins are not all associated with the plasma membrane and are targeted to different destinations in the cell, biochemical experiments have determined the PHB-containing proteins to be associated with lipid rafts (Morrow and Parton 2005). Interestingly, our team has recently demonstrated that MPP1 directly binds flotillins (Biernatowska et al. 2017). This finding raises another important question - whether flotillins have an effect on the mechanism underlying the interaction of MPP1 with membrane lipids. As expected, the results obtained from the flotation assay of purified recombinant flotillin-1 and flotillin-2 with erythrocyte membrane-like liposomes indicated that both flotillin-1 and flotillin-2 interact with membrane lipids (Fig. 6A). To this end, we asked whether flotillins, being MPP1- and lipid-binding proteins, affect the binding of MPP1 to membrane lipids. To answer this question, the binding of MPP1 and erythrocyte-like liposomes was conducted in the presence of flotillins using the flotation assay. Briefly, liposomes were incubated with MPP1:flotillin-1 (1:1), MPP1:flotillin-2 (1:1), and MPP1:flotillin-1:flotillin-2 (1:1:1) mixtures. After flotation with liposomes, the dot- 
blot assay of the gradient fractions was visualized using anti-MPP1 antibodies. Notably, when MPP1 was mixed with flotillins, flotillin-1 or flotillin-2 or both flotillin-1 and flotillin-2, a considerable fraction of MPP1 was preserved in the top fraction of the flotation gradient (Fig. 6B). These results show that the protein-protein and protein-lipid binding activities of flotillins do not perturb the binding of MPP1 to membrane lipids.

To gain a deeper insight into the interaction of studied proteins with membrane lipids, the exclusion surface pressure of MPP1 and flotillins was determined from the penetration ability of these proteins into erythrocyte membranelike monolayers. The exclusion pressure provides a surface pressure threshold for the tested proteins beyond which the protein does not penetrate the lipid monolayer. Fig. 7 shows that the surface pressure increases $(\Delta \pi)$ in monolayers upon the injection of MPP1, flotillin-1, or flotillin-2, at various initial surface pressures $\left(\Delta \pi=\pi_{\text {final }}-\pi_{\text {initial }}\right)$. For these three proteins, the greater the $\pi_{\text {initial }}$, the lower the incorporation of the protein into the monolayer as a consequence of greater lipid packing at higher initial surface pressures.
These values show that the proteins could penetrate better into lipid monolayers which are in an expanded state. The determined exclusion surface pressure for MPP1, flotillin-1 and flotillin-2 into the erythrocyte-like monolayers at the lipid monolayer/buffer interface was determined to be 30 , 35 and $27 \mathrm{mNm}^{-1}$, respectively. The results obtained from this set of experiments confirm that these proteins, as single protein components, bind membrane lipids. Furthermore, the determined exclusion surface pressure of flotillin-1 $\left(35 \mathrm{mNm}^{-1}\right)$ raises the possibility that flotillin-1 could penetrate, at least partially, into the membrane bilayer.

\section{Discussion}

It has been found that MPP1 regulates the formation of raft-like domains in the erythrocyte cell membrane and the lack of MPP1 resulted in significant changes in the physicochemical properties of the plasma membrane (Biernatowska et al. 2013; Podkalicka et al. 2015). However, the detailed mechanism underlying the participation of MPP1 in the
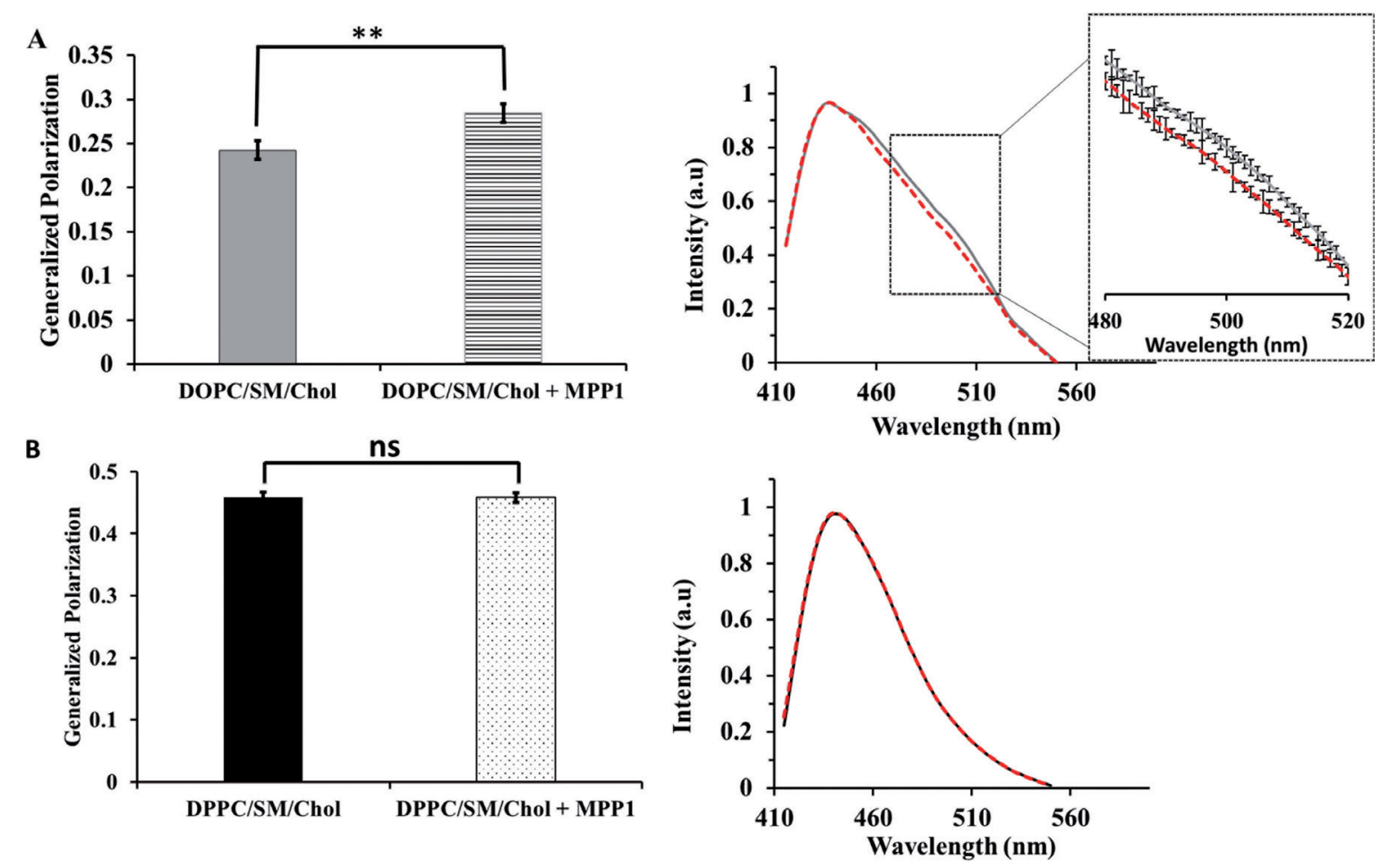

Figure 5. Generalized polarization (GP) sensitivity of environment-sensitive probes to the lateral heterogeneity of two lipid mixtures composed of DOPC/SM/Chol (grey) in comparison with DPPC/SM/Chol (black) upon addition of MPP1. A. GP values of DOPC/SM/ Chol liposomes alone and in the presence of MPP1. Inset: Sample normalized spectra of C-Laurdan in DOPC/SM/Chol liposomes (grey line), and DOPC/SM/Cho liposomes with MPP1 (dashed red line). B. GP values of DPPC/SM/Chol liposomes alone and in the presence of MPP1. Inset: Sample normalized spectra of C-Laurdan in DPPC/SM/Chol liposomes (dashed black line), and DPPC/SM/Chol liposomes with MPP1 (red line). Student's $t$-test was applied in comparison of the data obtained for DOPC/SM/Chol liposomes vs DOPC/ $\mathrm{SM} /$ Chol liposomes with MPP1. ${ }^{* *} p<0.01$. Results here are mean $\pm \mathrm{SD}(n=3)$. ns, non-significant. For more abbreviations, see Fig. 1. 
plasma membrane remains to be explored. In this context, we have shown recently that MPP1 interacts with lipid mono- and bilayers composed of DOPC, SM and cholesterol, suggesting that such interaction could be involved in the association of MPP1 with plasma membrane (Elderdfi et al. 2017). In the next step of our study, presented here, we quantitatively investigated the effect of the surrounding membrane environment on the binding of MPP1 with membrane lipids. The results obtained from the FRET-based method indicated that the binding affinity of MPP1 with liposomes composed of DOPC/SM/Chol is approximately two-fold higher than the values obtained with liposomes composed of DOPC/SM without cholesterol $\left(\mathrm{K}_{\mathrm{D}} \sim 135\right.$ $\pm 15 \mathrm{nM}$ and $\sim 220 \pm 47 \mathrm{nM}$, respectively) (Figs. 1A, 1B). It should be noted that these are the first $K_{D}$ values obtained for this interaction using a quantitative assay. These observations are similar to results obtained previously for Langmuir lipid monolayers prepared from lipid mixtures composed of DOPC and SM with and without cholesterol (Elderdfi et al. 2017), wherein the addition of MPP1 to the subphase buffer resulted in a larger increase in area-per-molecule values in the presence of cholesterol, compared to those observed in the absence of cholesterol.

Assuming that the $\mathrm{C} / \mathrm{F}$ mutation really mimics the native palmitoylation of the molecule (Ruff et al. 1991; Yang et al. 2010), FRET results obtained from the experiment using the C242F mutant mimicking palmitoylated MPP1 suggests that the protein palmitoylation at single site was not crucial for binding of the MPP1 with membrane lipids (Fig. 1C). This was also confirmed by using the Langmuir monolayer technique (Fig. 1D). One possibility is that the palmitoylation in MPP1 might serve as a plasma membrane localization signal. This mechanism of action has also been suggested in other peripheral membrane proteins (Liu et al. 2005). It is important to note that MPP1 palmitoylation has been considered to have a role in the association of MPP1 with membranes or even take part in the generation of lateral inhomogeneity.

Proteins are often excluded from cholesterol-rich membrane regions because cholesterol induces tighter membrane lipid packing (Head et al. 2014). Nevertheless, certain types of proteins are known to segregate with cholesterol and preferentially associate with cholesterol-rich membrane regions.
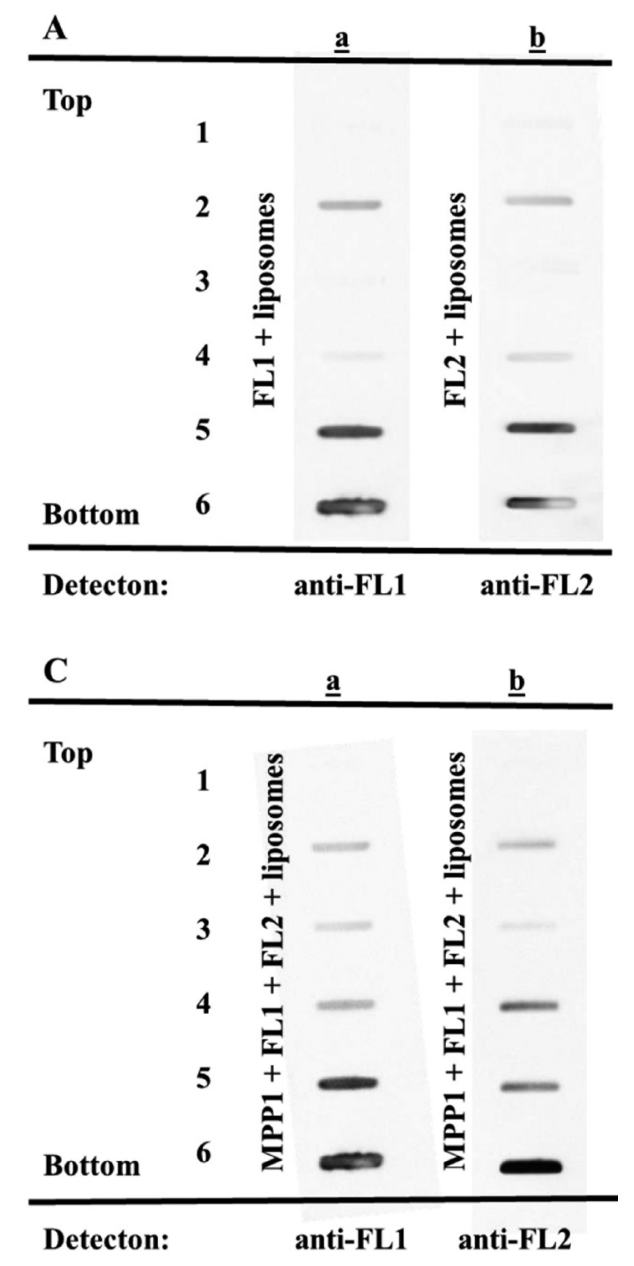

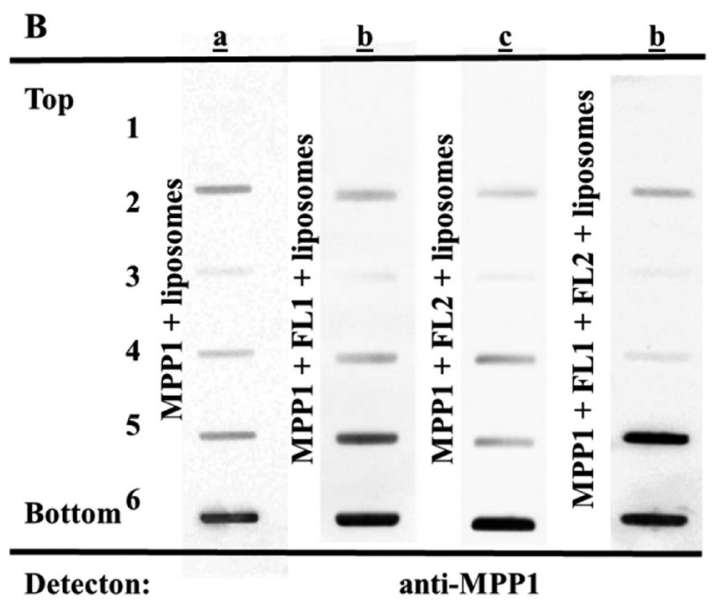

Figure 6. Effect of flotillins on association of MPP1 with erythrocyte membrane-like liposomes using the flotation assay. A. Flotation fractions analysis of binding of flotillin-1 (lane a) and flotillin-2 (lane b) with liposomes. B. Flotation fractions analysis of binding of MPP1 alone (lane a) with lipid liposomes, and in the presence of flotillin-1 (lane b), flotillin-2 (lane c), and flotillin-1/flotillin-2 (lane d). C. Flotation fractions analysis of binding of flotillin-1 (lane a) and flotillin-2 (lane b) with liposomes.in the presence of flotillin-1/flotillin-2/MPP1. The sucrose gradient fractions were analyzed by the dot-blot assay and flotillin-1, flotillin-2 and MPP1 were visualized using anti-flotillin-1, anti-flotillin-2 and anti-MPP1 antibodies, respectively. 


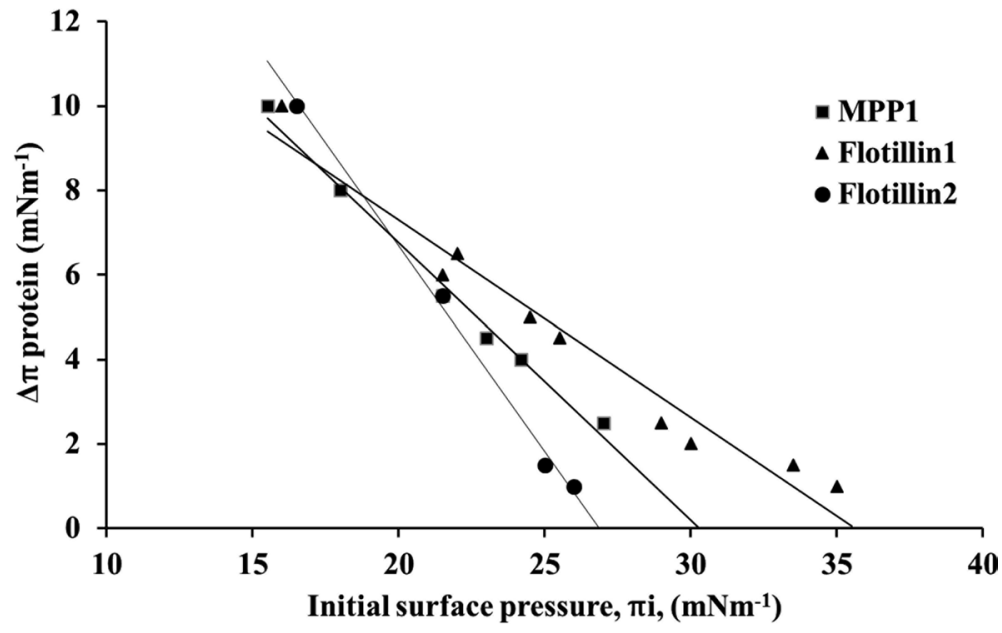

Figure 7. Determination of exclusion surface pressures. Change in the surface pressure $\left(\pi_{\text {final }}-\pi_{\text {initial }}\right)$ $v s$. initial surface pressure $\left(\pi_{\text {initial }}\right)$ for MPP1 (black squares), flotillin-1 (black triangles), and flotillin-2 (black circles) adsorption on an erythrocyte membrane-like monolayer.
Our recent study showed that the interaction of MPP1 with lipid monolayers is enhanced in the presence of cholesterol in the monolayer lipid mixture (Elderdfi et al. 2017). Here we asked a further question, namely, whether this interaction might involve direct binding of cholesterol by MPP1, as it is known that MPP1 contains in its structure surface-exposed cholesterol-binding CRAC and CRAC-like motifs which were found to be able to bind cholesterol with reasonable affinity in simple modeling studies (Listowski et al. 2015). Using the constant surface area monolayer approach, the binding of MPP1 with lipid membranes was observed to be specifically inhibited as a consequence of the formation of cholesterol/MPP1 complex(es) in a competition assay. This finding was derived from the observation that the preincubation of MPP1 with cholesterol prior to its addition to the lipid monolayer significantly reduced the binding of MPP1 into lipid monolayers in comparison with the binding of pre-incubated cholesterol-free MPP1 (Fig. 3B). These results indicate the formation of stable complexes between pre-incubated-MPP1/cholesterol, which in turn prevent MPP1 insertion into the lipid monolayer. In addition, several studies have proposed a similar mechanism of action for another cholesterol-binding protein, i.e. caveolin (Okamoto et al. 1998; Williams and Lisanti 2004; Epand 2008, 2006). They have shown that binding of caveolin with cholesterol is directly related to the CRAC domain ( $\mathrm{Li}$ et al. 1996; Yang et al. 2014) and the insertion of caveolin into phosphatidylcholine membranes is dependent on the presence of cholesterol (Smart and Anderson 2002; Ortegren et al. 2004). Furthermore, the membrane insertion of a chloride intracellular ion channel protein (CLIC1) into lipid monolayers was found to be inhibited when CLIC1 protein was pre-incubated with cholesterol before its addition to the subphase, providing evidence that the CLIC1 insertion into cholesterol-containing monolayers involves direct binding between CLIC1 and cholesterol molecules (Hossain et al. 2016). Taking into consideration that MPP1 probably forms a complex(es) with cholesterol which inhibits the MPP1 insertion into the lipid (erythrocyte membrane-like) monolayer, we suggest that the interaction of MPP1 with cholesterol-containing lipids would be highly likely to involve direct binding between MPP1 and cholesterol molecules.

To expand our ability to examine the effect of the lipid lateral heterogeneity, the interaction of MPP1 with membrane lipids was investigated using two lipid mixtures, corresponding to phase separated or homogeneous lipid mono- and bilayers. In both cases we observed different results. In the monolayer system the change in the surface pressure values of DOPC-containing monolayers after the addition of $10 \mathrm{nM}$ MPP1 (10 nM; less than the equilibrium concentration) into the subphase buffer was significantly $(p<0.01)$ smaller than those observed for DPPC-containing monolayers, while in the case of DOPC-containing liposomes the amount of bound MPP1 (50 nM) was significantly larger.

This discrepancy, in our opinion, results from the different experimental systems. In the liposomal system (flotation assay) the observed final result does not include a change in lateral packing density of lipids, while in the Langmuir monolayer the packing density of lipids has a significant effect on the surface pressure value. This interpretation is schematically illustrated in Supporting Information Fig. S3. Indeed, in comparison with DPPC monolayers, the DOPC monolayers are more compressible at a surface pressure of $20 \mathrm{mNm}^{-1}$. Therefore, we might expect a significant change in the area-per-molecule within the DOPC monolayer, and thus the interaction of MPP1 with DOPC-containing monolayers results in a smaller increase in the surface pressure compared to DPPC-containing monolayers. A similar mechanism of action was proposed elsewhere, illustrating a decrease in the $\Delta \pi$ values after the injection of lung annexin I (LAI) under lipid monolayers composed of POPG and the lack of a $\Delta \pi$ decrease in the case of lipid monolayers 
composed of DPPG (Koppenol et al. 1998). Nevertheless, it should be noted that the influence of the phase state of the lipid mixture on MPP1 binding using the liposome system and flotation assay is less stringent, although still marked.

An important issue is the response of C-Laurdan to changes in lipid packing, which shed some light on the effect of MPP1 binding on the physicochemical properties of these two lipid mixtures. Significantly, an increase in GP values of DOPC-containing liposomes upon the addition of MPP1 was noted, whereas no significant changes were determined in the GP values of DPPC-containing liposomes in the presence and absence of MPP1, indicating that modification of the lipid monolayer properties is not observed in the lipid liposomes exhibiting a homogeneous ordered phase. This appears consistent with our previous study in which lower GP values for vesicles isolated from MPP1-knockdown cells compared to control erythroid cells were observed (Podkalicka et al. 2015). In addition, fluorescence-lifetime imaging microscopy (FLIM) experiments of the di-4 probe detected, upon MPP1 expression silencing, changes in the plasma membrane order of giant plasma membrane vesicles (GPMVs) isolated from HEL cells (Biernatowska et al. 2013). From these observations, we can conclude that the influence of MPP1 on physicochemical properties of the lipid membranes is sensitive to subtle changes in the phase state of the lipid mixture.

We became interested in flotillins when our team recently identified these proteins as binding partners for MPP1 in the erythrocyte membrane (Biernatowska et al. 2017). Both flotillin-1 and flotillin-2 have been shown to be associated with membrane rafts (Salzer and Prohaska 2001; Liu et al. 2005; Stuermer and Plattner 2005; Rivera-Milla et al. 2006; Babuke and Tikkanen 2007; Sasaki et al. 2008; Stuermer 2010; Koh et al. 2016; Bodrikov et al. 2017). They are also well known to form homo- and hetero-oligomers (1:1) (Salzer and Prohaska 2001; Rivera-Milla et al. 2006; Solis et al. 2007, 2010; Babuke et al. 2009). Using the liposome flotation assay, flotillin-1 and flotillin-2 were found to associate with the lipid liposome at the top of the flotation gradient, indicating that flotillins, as single protein components, have the capability to bind liposomes (Fig. 6A). Remarkably, no significant changes were observed in the lipid-binding activity of MPP1 in the presence of flotillins compared to MPP1 alone (Fig. 6B), implying that the protein-protein binding activity of these proteins as well as the flotillin-lipid binding activities did not perturb the interaction of MPP1 with liposomes. Furthermore, both flotillin-1 and flotillin-2 were also detected, with MPP1, at the top fraction of the sucrose gradient (Fig. 6C). Together, these observations may suggest that at least recombinant flotillins do not affect interactions of recombinant MPP1 with membrane lipids.

The ability of flotillin- 1 to penetrate the lipid monolayer up to a surface pressure of $35 \mathrm{mNm}^{-1}$ in comparison with flotillin-2 $\left(26 \mathrm{mNm}^{-1}\right)$ is worth mentioning because it provides evidence that flotillin-1 could, at least partially, penetrate the plasma membrane (the surface pressure of the physiological cell membrane is typically in the range 25-35 $\mathrm{mNm}^{-1}$ (Demel et al. 1975; Portlock et al. 1992; Marsh, 1996; Espinosa et al. 2011; Fantini et al. 2015; Stillwell and Stillwell 2016; review Elderdfi and Sikorski 2018). Although our results concerning flotillins do not allow us to draw strong conclusions on the effect of flotillins on binding activity of MPP1 and membrane lipids, they strengthen the previous suggestion in the literature that flotillin-1 is able to penetrate the membrane (Saltiel et al. 2000; Dermine et al. 2001; Gkantiragas et al. 2001; Morrow et al. 2002). Further studies are necessary in order to investigate the role of flotillins, in particular flotillin-1, in the mechanism of the membrane association of MPP1 in erythroid cells.

In conclusion, our results provide some insights into the mechanism underlying the association of MPP1 with membrane lipids. Interestingly, we showed by using the C242F mutant mimicking palmitoylated MPP1 that this modification probably does not play a critical role in MPP1 binding with artificial lipid membranes. Furthermore, flotillins, as single protein components, interact with membrane lipids, with flotillin-1, in particular, able to also act as a membrane penetrating protein. However, their effect on MPP1-lipid bilayer interaction was not detectable in our experimental system. Although there are variations in the binding characteristics of MPP1 with different membrane lipids, the influence of MPP1 on physicochemical properties of lipid membranes appears to be affected by subtle changes in the phase state of the lipid mixture. The Langmuir monolayer experiments show that the MPP1: cholesterol complex induced a substantial decrease in surface pressure change of the cholesterol-containing monolayer compared to MPP1 alone, suggesting an apparent ability of MPP1 to directly interact with cholesterol molecules. We suggest the possibility that such interactions could be involved in the mechanism of the membrane association of MPP1 and may participate in the mechanism of MPP1-dependent raft domain organization and regulation in erythroid cell plasma membranes.

Acknowledgements. M.E. expresses his gratitude for financial support from the Embassy of Libya in Warsaw, Poland. We would like to thank Dr. Aleksander Czogalla for his help and valuable discussions. We are grateful to Dr. Katarzyna Augoff for sharing with us the $\mathrm{C} 242 \mathrm{~F}$ mutant-mimicking palmitoylated MPP1. The study was supported by NCN Grant 2016/21/B/NZ1/02821 to Aleksander Czogalla.

\section{References}

Babuke T, Ruonala M, Meister M, Amaddii M, Genzler C, Esposito A, Tikkanen R (2009): Hetero-oligomerization of reggie-1/flo- 
tillin-2 and reggie-2/flotillin-1 is required for their endocytosis. Cell. Signal. 21, 1287-1297

https://doi.org/10.1016/j.cellsig.2009.03.012

Babuke T, Tikkanen R (2007): Dissecting the molecular function of reggie/flotillin proteins. Eur. J. Cell Biol. 86, 525-532 https://doi.org/10.1016/j.ejcb.2007.03.003

Bangham AD., Standish MM, Watkins JC (1965): Diffusion of univalent ions across the lamellae of swollen phospholipids. J. Mol. Biol. 13, 238-252

https://doi.org/10.1016/S0022-2836(65)80093-6

Bernardino S. J, Schütz G.J, Eggeling C, Cebecauer M (2016): There is no simple model of the plasma membrane organization. Front. Cell Dev. Biol. 4, 106 https://doi.org/10.3389/fcell.2016.00106

Bhojoo U, Chen M, Zou S (2018): Temperature induced lipid membrane restructuring and changes in nanomechanics. Biochim. Biophys. Acta 1860, 700-709 https://doi.org/10.1016/j.bbamem.2017.12.008

Biernatowska A, Podkalicka J, Majkowski M, Hryniewicz-Jankowska A, Augoff K, Kozak K, Korzeniewski J, Sikorski AF (2013): The role of MPP1/p55 and its palmitoylation in resting state raft organization in HEL cells. Biochim. Biophys. Acta 1833, 1876-1884 https://doi.org/10.1016/j.bbamcr.2013.03.009

Biernatowska A, Augoff K, Podkalicka J, Tabaczar S, GajdzikNowak W, Czogalla A, Sikorski AF (2017): MPP1 directly interacts with flotillins in erythrocyte membrane - Possible mechanism of raft domain formation. Biochim. Biophys. Acta 1859, 2203-2212 https://doi.org/10.1016/j.bbamem.2017.08.021

Boal F, Mansour R, Gayral M, Saland E, Chicanne G, Xuereb JM, Marcellin M, Burlet-Schiltz O, Sansonetti PJ, Payrastre B, Tronchère $\mathrm{H}$ (2015): TOM1 is a PI5P effector involved in the regulation of endosomal maturation. J. Cell Sci. 128, 815-827 https://doi.org/10.1242/jcs.166314

Bodrikov V, Pauschert A, Kochlamazashvili G, Stuerme CAO (2017): Reggie-1 and reggie-2 (flotillins) participate in Rab11adependent cargo trafficking spine synapse formation and LTPrelated AMPA receptor (GluA1) surface exposure in mouse hippocampal neurons. Exp. Neurol. 289, 31-45 https://doi.org/10.1016/j.expneurol.2016.12.007

Busse RA, Scacioc A, Hernandez JM, Krick R, Stephan M, Janshoff A, Thumm M, Kühnel K (2013): Qualitative and quantitative characterization of protein-phosphoinositide interactions with liposome-based methods. Autophagy 9, 770-777 https://doi.org/10.4161/auto.23978

Carquin M, D‘Auria L, Pollet H, Bongarzone ER, Tyteca D (2016): Recent progress on lipid lateral heterogeneity in plasma membranes: From rafts to submicrometric domains. Prog. Lipid Res. 62, 1-24 https://doi.org/10.1016/j.plipres.2015.12.004

Demel RA, Geurts van Kessel WSM, Zwaal RFA, Roelofsen B, van Deenen LLM (1975): Relation between various phospholipase actions on human red cell membranes and the interfacial phospholipid pressure in monolayers. Biochim. Biophys. Acta 406, 97-107 https://doi.org/10.1016/0005-2736(75)90045-0

Dermine JF, Duclos S, Garin J, St-Louis F, Rea S, Parton RG, Desjardins M (2001): Flotillin-1-enriched lipid raft domains accumulate on maturing phagosomes. J. Biol. Chem. 276, 18507-18512
https://doi.org/10.1074/jbc.M101113200

DeWolf C, McCauley P, Sikorski AF, Winlove CP, Bailey AI, Kahana E, Pinder JC, Gratzer WB (1997): Interaction of dystrophin fragments with model membranes. Biophys. J. 72, 2599-2604 https://doi.org/10.1016/S0006-3495(97)78903-3

Dimitratos SD, Woods DF, Stathakis DG, Bryant PJ (1999): Signaling pathways are focused at specialized regions of the plasma membrane by scaffolding proteins of the MAGUK family. BioEssays 21, 912-921

https://doi.org/10.1002/(SICI)1521-1878(199911)21:11<912::AID-BIES3>3.0.CO;2-Z

Edidin M (2003): The state of lipid rafts: from model membranes to cells. Annu. Rev. Biophys. Biomol. Struct. 32, 257-283 https://doi.org/10.1146/annurev.biophys.32.110601.142439

Efimova SS, Ostroumova OS (2017): Dipole modifiers regulate lipid lateral heterogeneity in model membranes. Acta Naturae 9, 67-74

Elderdfi M, Zegarlińska J, Jones W, Sikorski AF (2017): MPP1 interacts with DOPC/SM/Cholesterol in an artificial membrane system using Langmuir-Blodgett monolayer. Gen. Physiol. Biophys. 36, 443-454 https://doi.org/10.4149/gpb_2017002

Elderdfi M, Sikorski AF (2018): Langmuir-monolayer methodologies for characterizing protein-lipid interactions. Chem. Phys. Lipids 212, 61-72 https://doi.org/10.1016/j.chemphyslip.2018.01.008

Epand RM (2006): Cholesterol and the interaction of proteins with membrane domains. Prog. Lipid Res. 45, 279-294 https://doi.org/10.1016/j.plipres.2006.02.001

Epand RM (2008): Proteins and cholesterol-rich domains. Biochim. Biophys. Acta 1778, 1576-1582 https://doi.org/10.1016/j.bbamem.2008.03.016

Espinosa G, López-Montero I, Monroy F, Langevin D (2011): Shear rheology of lipid monolayers and insights on membrane fluidity. Proc. Natl. Acad. Sci. USA 108, 6008-6013 https://doi.org/10.1073/pnas.1018572108

Fantini J, Yahi N, Fantini J, Yahi N (2015): Protein-lipid interactions in the brain. In: Brain Lipids in Synaptic Function and Neurological Disease, pp. 135-162, Elsevier https://doi.org/10.1016/B978-0-12-800111-0.00006-0

Fritzsching KJ, Kim J, Holland GP (2013): Probing lipid-cholesterol interactions in DOPC/eSM/Chol and DOPC/DPPC/Chol model lipid rafts with DSC and 13C solid-state NMR. Biochim. Biophys. Acta 1828, 1889-1898 https://doi.org/10.1016/j.bbamem.2013.03.028

Gilbert GE, Furie BC, Furie B (1990): Binding of human factor VIII to phospholipid vesicles. J. Biol. Chem. 265, 815-822

Gkantiragas I, Brügger B, Stüven E, Kaloyanova D, Li XY, Löhr K, Lottspeich F, Wieland FT, Helms JB (2001): Sphingomyelinenriched microdomains at the Golgi complex. Mol. Biol. Cell 12, 1819-1833 https://doi.org/10.1091/mbc.12.6.1819

Gómez-Móuton C, Abad JL, Mira E, Lacalle RA, Gallardo E, Jiménez-Baranda S, Illa I, Bernad A, Ma-es S, Martínez-A C (2001): Segregation of leading-edge and uropod components into specific lipid rafts during T cell polarization. Proc. Natl. Acad. Sci. USA 98, 9642-9647 
https://doi.org/10.1073/pnas.171160298

Goni FM, Alonso A, Bagatolli LA, Brown RE, Marsh D, Prieto M, Thewalt JL (2008): Phase diagrams of lipid mixtures relevant to the study of membrane rafts. Biochim. Biophys. Acta 1781, 665-684 https://doi.org/10.1016/j.bbalip.2008.09.002

Hancock JF 2006. Lipid rafts: contentious only from simplistic standpoints. Nat. Rev. Mol. Cell Biol. 7, 456-462 https://doi.org/10.1038/nrm1925

Hossain KR, Al Khamici H, Holt SA, Valenzuela1 SM (2016) Cholesterol promotes interaction of the protein CLIC1 with phospholipid monolayers at the air-water interface. Membranes 6,15 https://doi.org/10.3390/membranes6010015

Head BP, Patel HH, Insel PA (2014): Interaction of membrane/lipid rafts with the cytoskeleton: impact on signaling and function: membrane/lipid rafts, mediators of cytoskeletal arrangement and cell signaling. Biochim. Biophys. Acta 1838, 532-545 https://doi.org/10.1016/j.bbamem.2013.07.018

Hemming NJ, Anstee DJ, Staricoff MA, Tanner MJ, Mohandas N (1995): Identification of the membrane attachment sites for protein 4.1 in the human erythrocyte. J. Biol. Chem. 270, 5360-5366 https://doi.org/10.1074/jbc.270.10.5360

Henry S, Bercu NB, Bobo C, Cullin C, Molinari M, Lecomte S (2018): Interaction of $A \beta 1-42$ peptide or their variant with model membrane of different composition probed by infrared nanospectroscopy. Nanoscale 10, 936-940 https://doi.org/10.1039/C7NR07489A

Khan TK, Yang B, Thompson NL, Maekawa S, Epand RM, Jacobson K (2003): Binding of NAP-22, a calmodulin-binding neuronal protein, to raft-like domains in model membranes. Biochemistry $42,4780-4786$ https://doi.org/10.1021/bi0265877

Koh M, Yong HY, Kim ES, Son H, Jeon YR, Hwang JS, Kim MO, Cha Y, Choi WS, Noh DY, et al. (2016): A novel role for flotillin-1 in H-Ras-regulated breast cancer aggressiveness. Int. J. Cancer 138, 1232-1245 https://doi.org/10.1002/ijc.29869

Koppenol S, Tsao FH, Yu H, Zografi G (1998): The interaction of lung annexin I with phospholipid monolayers at the air/water interface. Biochim. Biophys. Acta 1369, 221-232 https://doi.org/10.1016/S0005-2736(97)00224-1

Levental I, Grzybek M, Simons K (2011): Raft domains of variable properties and compositions in plasma membrane vesicles. Proc. Natl. Acad. Sci. USA 108, 11411-11416 https://doi.org/10.1073/pnas.1105996108

Li S, Song KS, Lisanti MP (1996): Expression and characterization of recombinant caveolin. Purification by polyhistidine tagging and cholesterol-dependent incorporation into defined lipid membranes. J. Biol. Chem. 271, 568-573 https://doi.org/10.1074/jbc.271.1.568

Listowski MA, Leluk J, Kraszewski S, Sikorski AF (2015): Cholesterol interaction with the MAGUK protein family member, MPP1, via CRAC and CRAC-like motifs: an in silico docking analysis. PLoS One 10, e0133141 https://doi.org/10.1371/journal.pone.0133141

Liu J, DeYoung SM, Zhang M, Dold LH, Saltiel AR (2005): The stomatin/prohibitin/flotillin/HflK/C domain of flotillin-1 contains distinct sequences that direct plasma membrane localization and protein interactions in 3T3-L1 adipocytes. J. Biol. Chem. 280, 16125-16134

https://doi.org/10.1074/jbc.M500940200

Marfatia SM, Morais-Cabral JH, Kim AC, Byron O, Chishti AH (1997): The PDZ domain of human erythrocyte p55 mediates its binding to the cytoplasmic carboxyl terminus of glycophorin C. Analysis of the binding interface by in vitro mutagenesis. J. Biol. Chem. 272, 24191-24197

https://doi.org/10.1074/jbc.272.39.24191

Marsh D (1996): Lateral pressure in membranes. Biochim. Biophys. Acta 1286, 183-223 https://doi.org/10.1016/S0304-4157(96)00009-3

Maté S, Busto JV, García-Arribas AB, Sot J, Vazquez R, Herlax V, Wolf C, Bakás L, Go-i FM (2014): N-nervonoylsphingomyelin (C24:1) prevents lateral heterogeneity in cholesterol-containing membranes. Biophys. J. 106, 2606-2616 https://doi.org/10.1016/j.bpj.2014.04.054

Morrow IC, Rea S, Martin S, Prior IA, Prohaska R, Hancock JF, James DE, Parton RG (2002): Flotillin-1/reggie-2 traffics to surface raft domains via a novel golgi-independent pathway. J. Biol. Chem. 277, 48834-48841 https://doi.org/10.1074/jbc.M209082200

Morrow IC, Parton RG (2005): Flotillins and the PHB domain protein family: rafts, worms and anaesthetics. Traffic 6, 725-740 https://doi.org/10.1111/j.1600-0854.2005.00318.x

Okamoto T, Schlegel A, Scherer PE, Lisanti MP (1998): Caveolins, a family of scaffolding proteins for organizing „preassembled signaling complexes" at the plasma membrane. J. Biol. Chem. 273, 5419-5422 https://doi.org/10.1074/jbc.273.10.5419

Ortegren U, Karlsson M, Blazic N, Blomqvist M, Nystrom FH, Gustavsson J, Fredman P, Stralfors P (2004): Lipids and glycosphingolipids in caveolae and surrounding plasma membrane of primary rat adipocytes. Eur. J. Biochem. 271, 2028-2036 https://doi.org/10.1111/j.1432-1033.2004.04117.x

Parkkila P, Elderdfi M, Bunker A, Viitala T (2018): Biophysical characterization of supported lipid bilayers using parallel dual-wavelength surface plasmon resonance and quartz crystal microbalance measurements. Langmuir 34, 8081-8091 https://doi.org/10.1021/acs.langmuir.8b01259

Paulowski L, Gutsmann T, Kutscher T (2018): A step forward in the design of liposomes: symmetric \& asymmetric vesicles from lipid extracts. Biophys. J. 114, 380a Podkalicka J, Biernatowska A, Majkowski M, Grzybek M, Sikorski AF (2015): MPP1 as a factor regulating phase separation in giant plasma membranederived vesicles. Biophys. J. 108, 2201-2211 https://doi.org/10.1016/j.bpj.2015.03.017

Podkalicka J, Biernatowska A, Majkowski M, Grzybek M, Sikorski $\mathrm{AF}$ (2015): MPP1 as a factor regulating phase separation in giant plasma membrane-derived vesicles. Biophys. J. 108, 2201-2211 https://doi:10.1016/j.bpj.2015.03.017

Portlock SH, Lee Y, Tomich JM, Tamm LK (1992): Insertion and folding of the amino-terminal amphiphilic signal sequences of the mannitol and glucitol permeases of Escherichia coli. J. Biol. Chem. 267, 11017-11022 
Rivera-Milla E, Stuermer CAO., Málaga-Trillo E (2006): Ancient origin of reggie (flotillin), reggie-like, and other lipid-raft proteins: convergent evolution of the SPFH domain. Cell. Mol. Life Sci. 63, 343-357 https://doi.org/10.1007/s00018-005-5434-3

Rouser G, Siakotos AN, Fleischer S (1966): Quantitative analysis of phospholipids by thin-layer chromatography and phosphorus analysis of spots. Lipids 1, 85-86 https://doi.org/10.1007/BF02668129

Ruff P, Speicher DW, Husain-Chishti A (1991): Molecular identification of a major palmitoylated erythrocyte membrane protein containing the src homology 3 motif. Proc. Natl. Acad. Sci. USA 88, 6595-6599 https://doi.org/10.1073/pnas.88.15.6595

Saltiel AR, Baumann CA, Ribon V, Kanzaki M, Thurmond DC, Mora S, Shigematsu S, Bickel PE, Pessin JE (2000): CAP defines a second signalling pathway required for insulin-stimulated glucose transport. Nature 407, 202-207 https://doi.org/10.1038/35025089

Salzer U, Prohaska R (2001): Stomatin, flotillin-1, and flotillin-2 are major integral proteins of erythrocyte lipid rafts. Blood 97, 1141-1143 https://doi.org/10.1182/blood.V97.4.1141

Sánchez-Martín MJ, Haro I, Alsina MA, Busquets MA, Pujol M (2010): A Langmuir monolayer study of the interaction of E1(145-162) hepatitis G virus peptide with phospholipid membranes. J. Phys. Chem. B 114, 448-456 https://doi.org/10.1021/jp906900k

Sasaki Y, Oshima Y, Koyama R, Maruyama R, Akashi H, Mita H, Toyota M, Shinomura Y, Imai K, Tokino T (2008): Identification of flotillin-2, a major protein on lipid rafts, as a novel target of p53 family members. Mol. Cancer Res. 6, 395-406 https://doi.org/10.1158/1541-7786.MCR-07-0108

Seo PS, Jeong JJ, Zeng L, Takoudis CG, Quinn BJ, Khan AA, Hanada T, Chishti AH (2009). Alternatively spliced exon 5 of the FERM domain of protein 4.1R encodes a novel binding site for erythrocyte p55 and is critical for membrane targeting in epithelial cells. Biochim. Biophys. Acta 1793, 281-289 https://doi.org/10.1016/j.bbamcr.2008.09.012

Seveau S, Eddy RJ, Maxfield FR, Pierini LM (2001): Cytoskeletondependent membrane domain segregation during neutrophil polarization. Mol. Biol. Cell 12, 3550-3562 https://doi.org/10.1091/mbc.12.11.3550

Sezgin E, Sadowski T, Simons K (2014): Measuring lipid packing of model and cellular membranes with environment sensitive probes. Langmuir 30, 8160-8166 https://doi.org/10.1021/la501226v

Sikorski AF, Podkalicka J, Jones W, Biernatowska A (2015): Membrane rafts in the erythrocyte membrane: a novel role of MPP1p55. Adv. Exp. Med. Biol. 842, 61-78 https://doi.org/10.1007/978-3-319-11280-0_5

Simons K, Gerl MJ (2010): Revitalizing membrane rafts: new tools and insights. Nat. Rev. Mol. Cell Biol. 11, 688-699 https://doi.org/10.1038/nrm2977

Smart EJ, Anderson RGW (2002): Alterations in membrane cholesterol that affect structure and function of caveolae. Methods Enzymol. 353, 131-139 https://doi.org/10.1016/S0076-6879(02)53043-3
Solis GP, Hoegg M, Munderloh C, Schrock Y, Malaga-Trillo E, Rivera-Milla E, Stuermer CAO (2007): Reggie/flotillin proteins are organized into stable tetramers in membrane microdomains. Biochem. J. 403, 313-322 https://doi.org/10.1042/BJ20061686

Solis GP, Malaga-Trillo E, Plattner H, Stuermer CAO (2010): Cellular roles of the prion protein in association with reggie/flotillin microdomains. Front. Biosci. 15, 1075-1085 https://doi.org/10.2741/3662

Stillwell W, Stillwell W (2016): Long-range membrane properties. In: An Introduction to Biological Membranes, pp. 221-245, Elsevier https://doi.org/10.1016/B978-0-444-63772-7.00011-7

Stuermer CAO (2010): The reggie/flotillin connection to growth. Trends Cell Biol. 20, 6-13 https://doi.org/10.1016/j.tcb.2009.10.003

Stuermer CAO, Plattner H (2005): The „lipid raft“ microdomain proteins reggie-1 and reggie-2 (flotillins) are scaffolds for protein interaction and signalling. Biochem. Soc. Symp. 72, 109-118 https://doi.org/10.1042/bss0720109

Tronchere H, Boal F (2017): Liposome flotation assays for phosphoinositide-protein interaction. Bio-protocol 5, e2169 https://doi.org/10.21769/BioProtoc.2169

Virtanen JA, Cheng KH, Somerharju P (1998): Phospholipid composition of the mammalian red cell membrane can be rationalized by a superlattice model. Proc. Natl. Acad. Sci. USA 95, 4964-4969 https://doi.org/10.1073/pnas.95.9.4964

White B, Holcombe J (2007): Fluorescent peptide sensor for the selective detection of $\mathrm{Cu} 2+$. Talanta 71, 2015-2020 https://doi.org/10.1016/j.talanta.2006.09.009

Wilkins MR, Gasteiger E, Bairoch A, Sanchez JC, Williams KL, Appel RD, Hochstrasser DF (1999): Protein identification and analysis tools in the ExPASy server. Methods Mol. Biol. 112, 531-552

Williams TM, Lisanti MP (2004): The caveolin proteins. Genome Biol. 5, 214 https://doi.org/10.1186/gb-2004-5-3-214

Xu J, Wang F, Van Keymeulen A, Herzmark P, Straight A, Kelly K, Takuwa Y, Sugimoto N, Mitchison T, Bourne HR (2003): Divergent signals and cytoskeletal assemblies regulate self-organizing polarity in neutrophils. Cell 114, 201-214 https://doi.org/10.1016/S0092-8674(03)00555-5

Yang G, Xu H, Li Z, Li F (2014): Interactions of caveolin-1 scaffolding and intramembrane regions containing a CRAC motif with cholesterol in lipid bilayers. Biochim. Biophys. Acta 1838, 2588-2599

https://doi.org/10.1016/j.bbamem.2014.06.018

Yang W, Di Vizio D, Kirchner M, Steen H, Freeman MR (2010): Proteome scale characterization of human S-acylated proteins in lipid raft-enriched and non-raft membranes. Mol. Cell. Proteomics 9, 54-70 https://doi.org/10.1074/mcp.M800448-MCP200

Received: March 3, 2018

Final version accepted: August 7, 2018 